\title{
ADVANCED MANUFACTURING SYSTEMS AND ENTERPRISES: CLOUD AND UBIQUITOUS MANUFACTURING AND AN ARCHITECTURE
}

\author{
Dr Goran Putnik * \\ University of Minho, Faculty of Engineering, Braga, Portugal
}

In this paper, in the first part an introduction to development of the concepts of Ubiquitous and Cloud Manufacturing is presented, as a model of advanced manufacturing systems and enterprises. In the second part an architecture, that might guide the implementation and exploitation of the Ubiquitous and Cloud Manufacturing is presented through an informal and conceptual presentation.

Key words: Ubiquitous, Manufacturing systems, Enterprises, Clouds, Architecture, Paradigm

\section{INTRODUCTION}

The traditional Manufacturing was superseded. The new dynamic and global business model forced traditional production processes to change in the sense of to be integrated in a global chain of resources and stakeholders. The agility and quick reaction to market changes is essential, and the high availability and capacity to effectively "answer" to requirements is one of the main sustainability criterion.

"Globalization, innovation and ICT are transforming many sectors to anywhere, anytime platforms", towards an intelligent business model under "design anywhere, make anywhere, sell anywhere" paradigm [03]. We would add "anytime" too. Traditional suppliers and customers are "transformed" in services, where supplying or using profiles are a question of needs or context. One service (a Calculator, for instance) can execute (supply) something using other services (Add, Sub, Mult and Div operations) [15].

All these performances are considered on Ubiquitous and Cloud Manufacturing $[08,09,18]$ suggest a manufacturing versionof ubiquitous and cloud computing (respectively) - ubiquitous and cloud manufacturing - and manufacturing with direct adoption of ubiquitous and cloud computing technologies. In this context, resources are seen as services, essentially. This manufacturing service-oriented network can stimulate productionoriented to service-oriented manufacturing [01].

Many of existent infra-structures are already ubiquitous and/or cloud based or are changing towards these virtual architecture. To use efficiently those infra-structures the applications must be transformed and follow services oriented applications pattern.

In this paper, in the first part an introduction to development of the concepts of Ubiquitous and Cloud Manufacturing is presented, as a model of advanced manufacturing systems and enterprises. In the second part an architecture, that might guide the implementation and exploitation of the Ubiquitous and Cloud Manufacturing is presented through an informal and conceptual presentation.

\section{MANUFACTURING AS SERVICE SYSTEMS}

Industrial and Product-Service Systems (IPS2) represents a "paradigm shift from the separated consideration of products and services to a new product understanding consisting of integrated products and services creates innovation potential to increase the sustainable competitiveness of mechanical engineering and plant design. The latter allows business models which do not focus on the machine sales but on the use for the customer e.g. in form of continuously available machines. The business model determines the complexity of delivery processes. Characteristics of Industrial Product-Service Systems allow covering all market demands" [05]. Figure 1 shows service offer of Mori Seiki, while Figure 2 and Figure 3 shows types of Product-Service Systems and scientific fields of action respectively. 


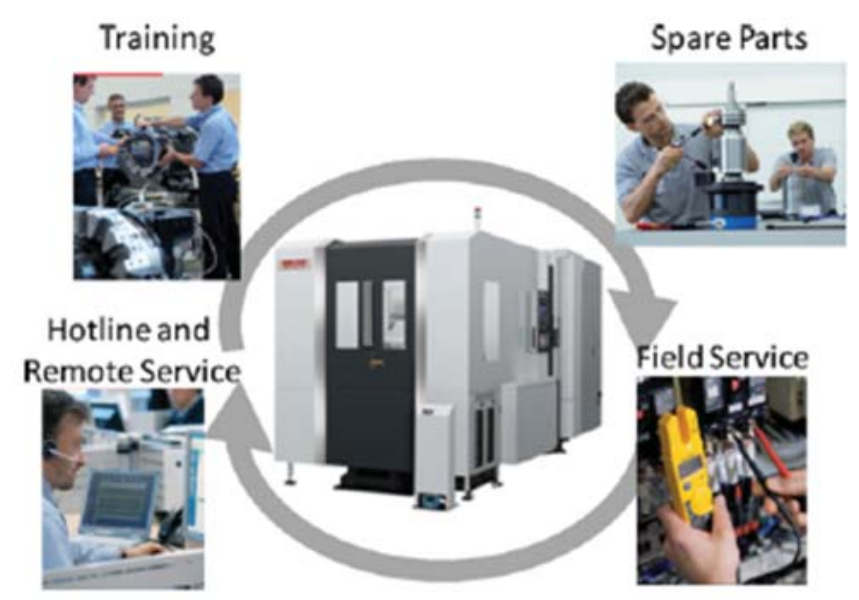

Figure 1: Service offer of Mori Seiki [06, 05].

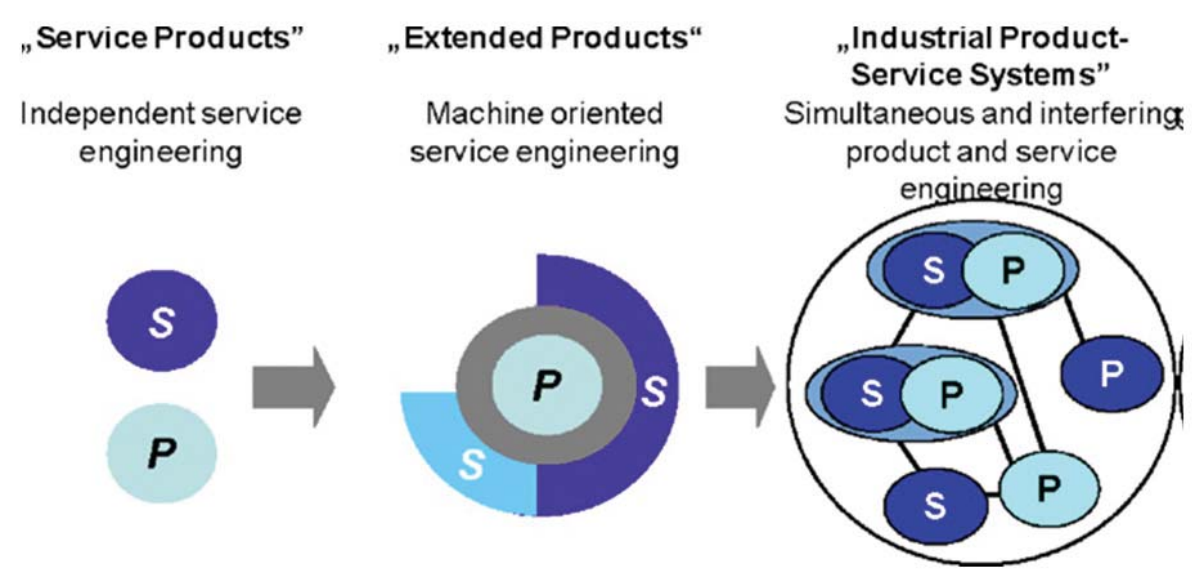

Figure 2: Types of Product-Service Systems [06,05]

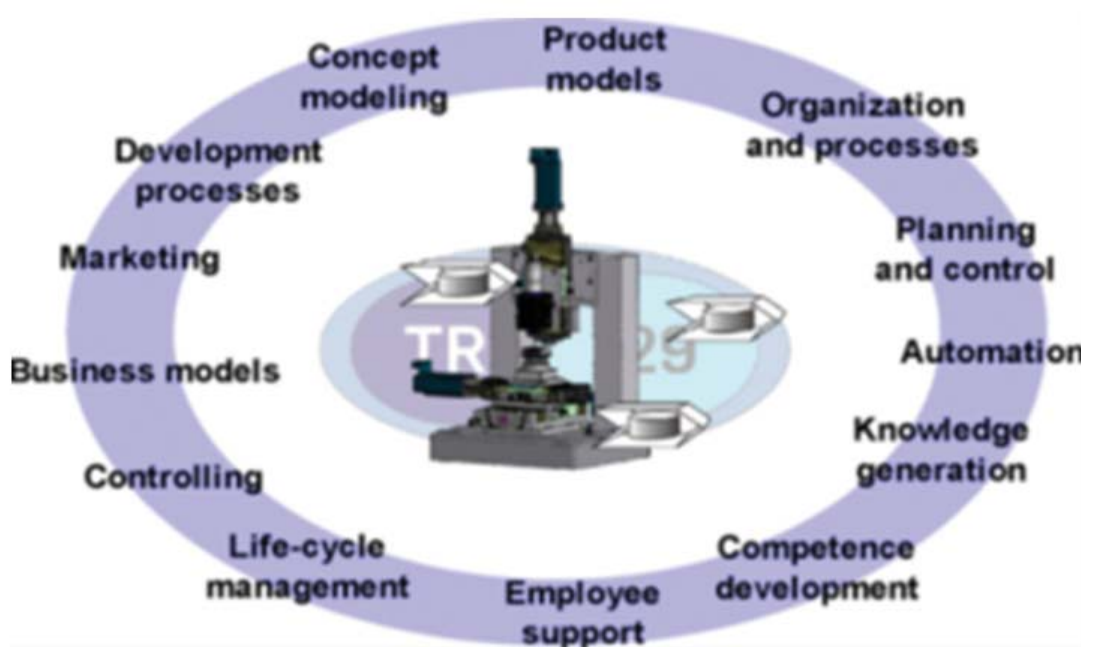

Figure 3: Scientific fields of action [05]

\section{UBIQUITOUS SYSTEMS}

Ubiquity is a synonym for omnipresence, the property of being present everywhere (Wikipedia). "The state or quality of being, or appearing to be, everywhere at once; actual or perceived omnipresence: the ability to be at all places at the same time; usually only attributed to God" (Wiktionary).
According to Weiser (1993) Ubiquitous Computing represents: "Long-term the PC and workstation will wither because computing access will be everywhere: in the walls, on wrists, and in "scrap computers" (like scrap paper) lying about to be grabbed as needed." 
Computing technology has evolved up to the point when Ubiquitous Computing System development and operation are possible, using present network devices, protocols and applications. From the other hand, ubiquity has been addressed in relation to manufacturing systems as well. In (Foust, 1975) [04] "the term "ubiquitous"' is "explicitly defined to be functional in an empirical context ... The types of manufacturing which are both market oriented and have a frequency of occurrence greater than a specific limit which can be empirically defined are ubiquitous. ...".

Foust (1975) cites Alfred Weber's definition of ubiquitous manufacturing too: "Ubiquity naturally does not mean that a commodity is present or producible at every mathematical point of the country or region. It means that the commodity is so extensively available within the region that, wherever a place of consumption is located, there are ... opportunities for producing it in the vicinity. Ubiquity is therefore not a mathematical, but a practical and approximate, term (praktischerNaherungsbegriff)."

To the above definitions (by (Foust, 1975) and (Weber, 1928)), [16] which consider ubiquity of resources - anywhere, we add the ubiquity in time - anytime, which (the "anytime"), from its "side", implies the dynamic, on-line, seamless, enterprises' organizational and manufacturing system networking and reconfigurability, or adaptability, that requires new organisational architectures and meta-enterprise organizations as creating and operating environments, makes the UMS a true new paradigm.
Theredore, Ubiquitous Manufacturing Systems and Enterprises concept is related to the availability of management, control and operation functions of manufacturing systems and enterprises anywhere, anytime, using direct control, notebooks or handheld devices. It is related with Ubiquitous Computing Systems.

Ubiquitous Manufacturing Systems (UMS), therefore, implies ubiquity of three general types of resources in organizations:

- material processing resources (e.g. machine tools and other manufacturing/production equipment as resources),

- information processing resources (e.g. computational resources - includes hardware and software), and

- knowledge resources (i.e. human resources, considering the humans as unique resources for knowledge generation and new products and services creation, and, at the end, the ultimate effectiveness of organizations).

However, there are two quite different approaches to the concept of UMS.

- The first concept, considers ubiquity of the MS based on, i.e. uses, the ubiquitous computational systems (UCS), Figure 4.a,

- The second one which is original our approach, considers ubiquity of the MS as a homomorphism, i.e. it is a mapping, of the ubiquitous computational systems (UCS), Figure 4.b [08, 09, 10].

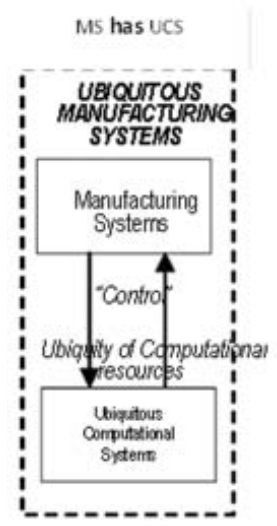

a)

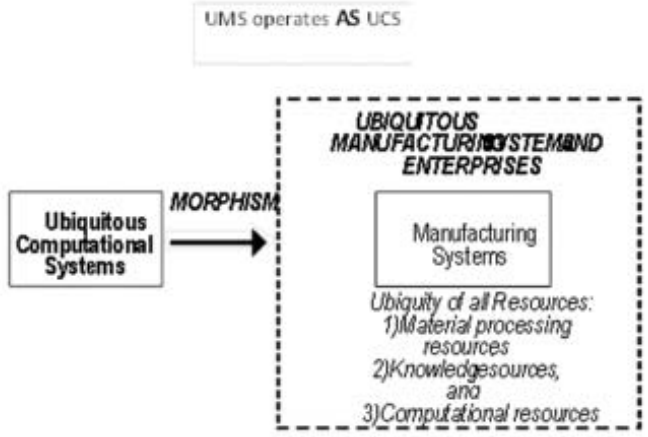

Figure 4: a) UMS has UCS as an operating system only - Ubiquity of Computational resources only; b) UMS operates as UCS - Ubiquity of all Resources: Material processing, Knowledge, and Computational resources [10]

The similar idea was referred in (Murakami \&Fujinuma; 2000), (ref. in (Serrano \& Fischer; 2007)). This approach is referred as well as "Ubiquitous networking" that "emphasises the possibility of building networks of persons and objects for sending and receiving information of all kinds 
and thus providing the users with services anytime and at any place".

The hypothesis is that UMS should be based on a "hyper"-sized manufacturing network, consisting of thousands, hundreds of thousands, or millions of "nodes", i.e. of manufacturing resources units, freely accessible and independent, Figure 5.

\section{Further implications are that}

1) UMS manufacturing units should be, in the limit,"primitive", i.e. individuals, or individual companies, and individually owned headwear/software resources,

2) Management and operation of UMS should ne informed by the discipline of "chaos and complexity management in organizations", e.g. Chaordic System Thinking (CST) model [02]

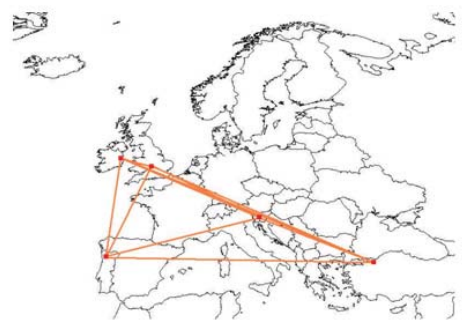

a)

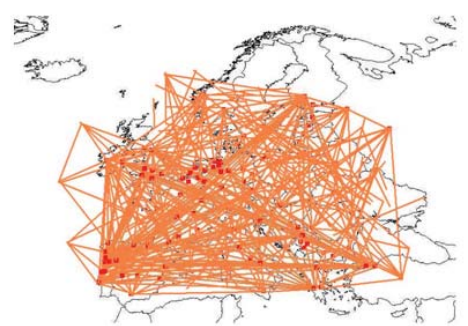

Figure 5: Figurative presentation of VE evolution: from conservative, minimal network domain (a), towards ubiquitous network domain (d)

"A 'cloud' is a platform or infrastructure that enables execution of code (services, applications etc.), in a managed and elastic fashion, whereas "managed" means that reliability according to pre-defined quality parameters is automatically ensured and "elastic" implies that the resources are put to use according to actual current requirements observing overarching requirement definitions - implicitly, elasticity includes both up- and downward scalability of resources and data, but also load-balancing of data throughput."
3) Specific instruments should be used, such as meta-organizations (e.g. Market of Resources model), brokering and virtuality,

4) These UMS "hyper"-sized manufacturing networks could be seen as manufacturing resources Internet of Things,

5) These UMS "hyper"-sized manufacturing networks could be seen as manufacturing production social networks,

6) These UMS "hyper"-sized manufacturing networks form and use clouds.

\section{CLOUD BASED PLATFORM}

Presentation of the 'cloud' is transcribed from (Schubert L., ...) - as the reference source created within the EC initiative and therefore it is the most relevant for an advanced Manufacturing Systems and/or enterprise.

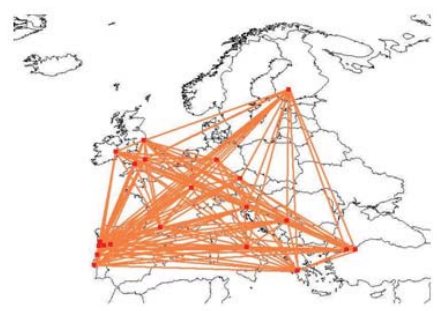

b)

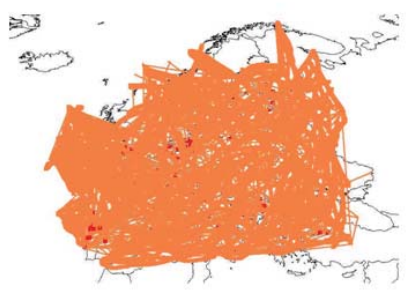

Cloud has a number of "particular characteristics that distinguish it from classical resource and service provisioning environments: (1) it is (more-or-less) infinitely scalable; (2) it provides one or more of an infrastructure for platforms, a platform for applications or applications (via services) themselves; (3) thus clouds can be used for every purpose from disaster recovery/business continuity through to a fully outsourced ICT service for an organisation; (4) clouds shift the costs for a business opportunity from CAPEX to OPEX which allows finer control of expenditure 
and avoids costly asset acquisition and maintenance reducing the entry threshold barrier; (5) currently the major cloud providers had already invested in large scale infrastructure and now offer a cloud service to exploit it; (6) as a consequence the cloud offerings are heterogeneous and without agreed interfaces; (7) cloud providers essentially provide datacentres for outsourcing; (8) there are concerns over security if a business places its valuable knowledge, information and data on an external service; (9) there are concerns over availability and business continuity - with some recent examples of failures; (10) there are concerns over data shipping over anticipated broadband speeds."

Concerning the EU policy towards clouds, the document refers two main recommendations:

Recommendation 1: The EC should stimulate research and technological development in the area of Cloud Computing

Recommendation 2: The EC together with Member States should set up the right regulatory framework to facilitate the uptake of Cloud computing

Concerning the types of clouds, for an advanced Manufacturing Systems and/or enterprise, the most important are the concepts of cloud types:

(1) laaS - Infrastructure as a Service, (2) PaaS - Platform as a Service, (3) SaaS - Software as a Service, and "collectively *aas (Everything as a Service) all of which imply a service-oriented architecture."

\section{AN OVERALL SYSTEM ARCHITECTURE FOR ADVANCED MANUFACTURING}

Advanced manufacturing system architecture, Figure 6, is a 'cloud' based architecture that represents the manufacturing system as a service system, integrating the services for

1) Real-time Data Acquisition Services for realtime data acquisition from the equipment through the embedded intelligent information devices - services type/group 'Equipment Intelligent Monitoring Systems',

2) Product Design Services, that integrates four environments: 1) Computer Aided Design, 2) Product data repository with embedded Intelligent System for Decision Making (for accessing all relevant data, actual and historic as well as data analysis) from the equipment in use, 3) Mixed-reality Environment, and 4) Co-Creation (Collaborative) Environment for co-creative design - services type/group 'Product Design Services';

3) Equipment Operation Services, that integrates four environments: 1) Equipment Data Real-time with embedded Intelligent System for Decision Making, that provides all relevant data, actual and historic as well as data analysis and management suggestions, necessary for the productuion management

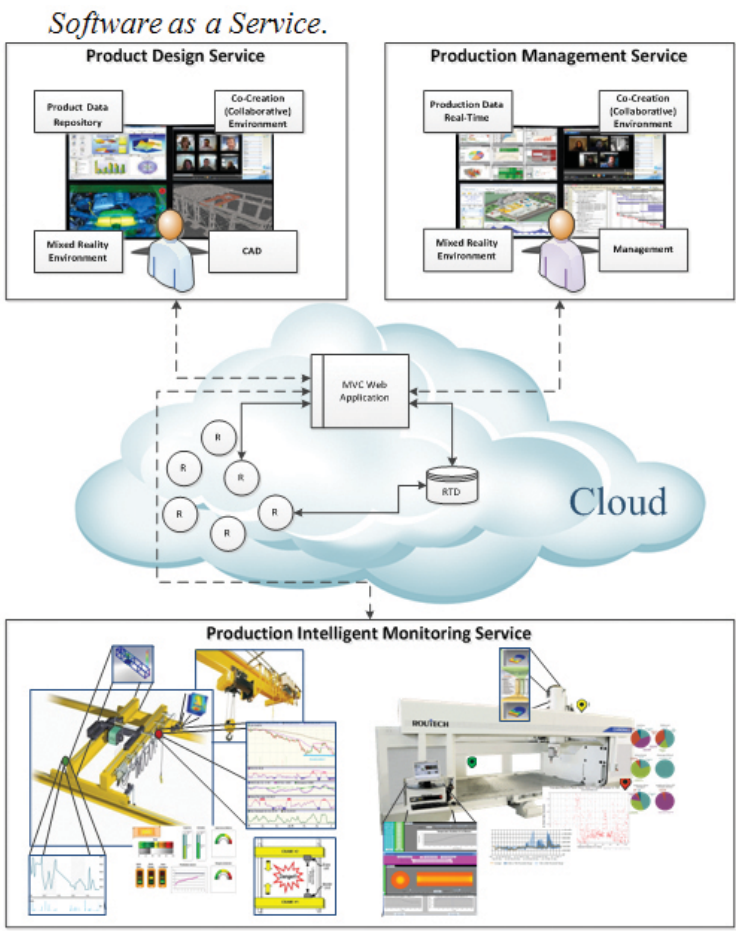

Figure 6: Overall System Architecture for development, implementation and validation 
2) Management environment, for monitoring, scheduling and controlling management activities, with embedded Intelligent System for Decision Making, 3) Mixed-reality Environment, and 4) Co-Creation (Collaborative) Environment for co-creative management - services;

4) The 'cloud' infrastructure, that will provide the 1) infrastructure for the manufacturing system applications - of all three types of resources: material processing resources, information processing resources (i.e. computational resources), and knowledge resources - in the form of laaS - Infrastructure as a Service; 2) platform for the manufacturing system applications in the form of PaaS - Platform as a Service, and 3) manufacturing system software 'business' applications in the form of SaaS - Software as a Service.

\section{ICT Platform Architecture}

The logical architecture of the ICT Platform is architecturefor integration of "Representation", "Mixed-reality representation", "Real-time management model", and "Communication for collaborative management".
It is basically a 3.tier layer architecture consisting of (1) Presentation Layer, (2) Business Layer and (3) Data Layer.

The 'Presentation Layer' represents/defines applications and support for all interfaces, views, presentations and communications for users.

The 'Business Layer' represents/defines applications and support for all 'business' applications such as Decision Making applications, Intelligent System applications, Services Workflows.

The ‘Data Layer' represents/defines applications and support for all applications for data repository and management, including knowledge bases (e.g. for Intelligent System on the upper level). For each layer the corresponding technology to be employed is referred.

\section{Co-Creation and Semiotics and Pragmatics platform}

Advanced manufacturing system architecture will integrate environments, or so-called, co-creative platforms, for three co-creative environments: 1) for product design processes, 2) for operation, or production, management processes, and 3) for integrated design-production processes.

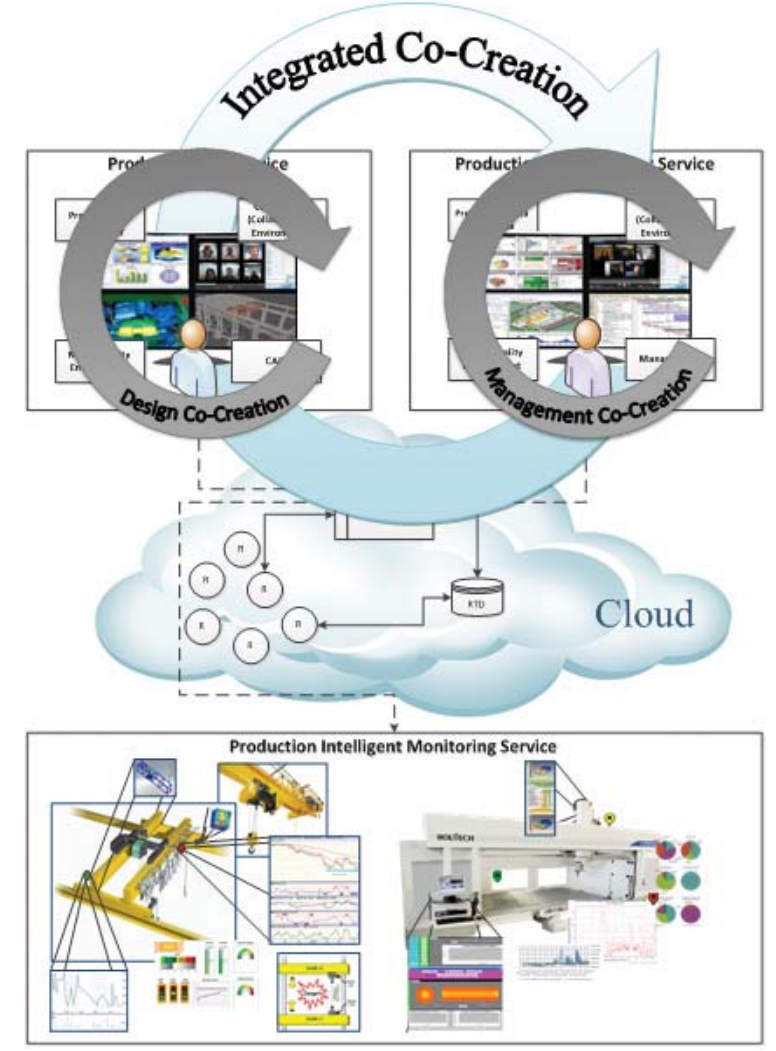

Figure 7: Advanced manufacturing system co-creative platform, for three co-creative environments: 1) for product design processes, 2) for operation, or production, management processes, and 3) for integrated design-production processes 


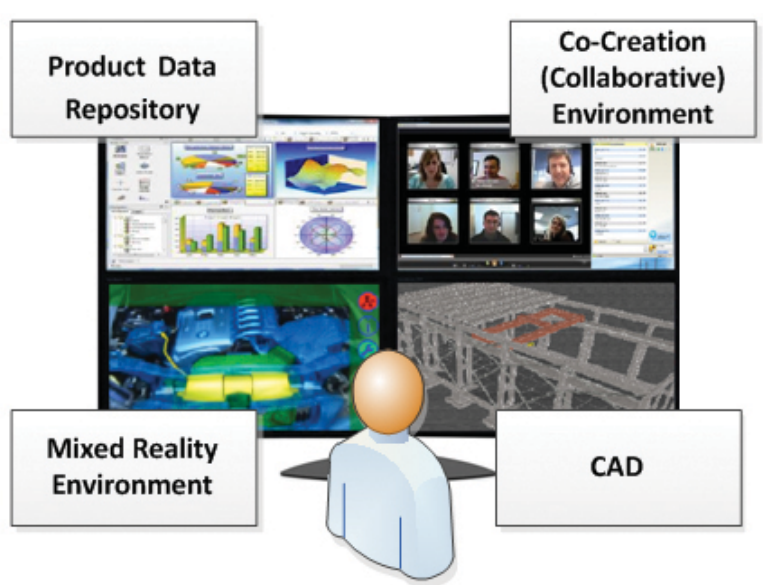

Figure 8: A vision of the multi-user video-conferencing system as the co-creative environment

It means that the co-creative processes both group of agents will perform independently, i.e. the designers will be capable to perform their processes in their own environment separately from the managers - ' 1 st Co-Creative cycle', and the managers will be be capable to perform their processes in their own environment separately from the designers- ' $2^{\text {nd }}$ Co-Creative cycle',. However, additionally, both groups will be capable to perform their processes jointly in a fully integrated and systemic way - ' 3 rd Co-Creative cycle', Figure 7.

The supporting technique will be the multi-user video-conferencing with auxiliary functionalities. A vision is presented on the Figure 8.

These three cycles, and the video-conferencing environment, will provide full semiotic/pragmatics effects and support in order to enhance to maximum the cognitive and creative capacities of the participants, and a full "co-creative", or codesign or co-evolving, and truly systemic environment.

\section{Sustainability}

The three aspects of sustainability: economic, environmental and social should be implemented in the following way: Figure 7 and Figure 8.

Economic and environmental sustainability: Economic and environmental sustainability will be based on implementation of specific softwaremodules, with corresponded analytical models, for continuous evaluation of energy consumption and costs, environmental pollution and associated costs.

These models and applications will be embedded in data acquisition services, see the System Architecture, Figure 15.
Social sustainability: Advanced manufacturing system components will support Social sustainability goals enabling "The creation of new jobs" This effect will be possible because the advanced manufacturing system is conceived as a service system meaning a great degree of "openness" for performing these services, the maintenance management and design services, by individuals ("free-lancers"), micro and small companies, that would form a dynamic network of services providers. In this way a potential for new jobs creation will be dramatically increased.

\section{CONCLUSIONS}

The architecture presented is of a general nature andopen in various aspects, with structural elements, in nature and in number, that enables development of an advanced manufacturing system or enterprise on different complexity levels - which is on of the primary requirements for the capacity of achieving sustainability. Therefore, the architecture presented may have a number of implementation forms.

It would be useful to remind that a number of underlying technologies should be considered, and which were not possible to analyze due to the paper's limited space. E.g. embedded intelligent information devices, real-time management (and design), mixed reality and augmented reality, semiotics and pragmatics, co-creation, chaos and complexity management, the theory of sustainability, web 2.0 to web 4.0, and others. In short, many of technologies are already present. However, from the other hand, there is a number of open technical, organizational and conceptual problems that requires hard work in the future. Two of the virtually most important problems to work on are the interoperability, or integration, of the Ubiquitous and Cloud Manufacturing and their adoption in society (and industry of course). 


\section{ACKNOWLEGMENTS}

The authors wish to acknowledge the support of:

1) The Foundation for Science and Technology

- FCT, Project PTDC/EME-GIN/102143/2008, 'Ubiquitous oriented embedded systems for globally distributed factories of manufacturing enterprises', 2) EUREKA, Project E! 4177-ProFactory UES

\section{REFERENCES}

1) Cheng, Y., Tao, F., Zhang, L., Zhang, $X ., X i$, G. H., \& Zhao, D. (2010).Study on the utility model and utility equilibrium of resource service transaction in cloud manufacturing. $\mathrm{Pa}-$ per presented at the Industrial Engineering and Engineering Management (IEEM), 2010

2) Eijnatten F., Putnik G., Sluga A. (2007) Chaordic Systems Thinking for Novelty in Contemporary Manufacturing, CIRPAnnals, Vol 56, No 1, pp. 447-450

3) Elliott, L. (2010). The Business of ICT in Manufacturing in Africa: Afribiz

4) Foust, Brady J. (1975) Ubiquitous Manufacturing, Annals of the Association of American Geographers, Vol. 65, No. 1 (March 1975), pp. 13-17

5) Meier H., Roy R., Seliger G. (2010) Industrial Product-Service Systems-IPS2, CIRP Annals Manufacturing Technology, 59 (2010) 607-627

6) Mori Seiki CO., LTD, Service/Support von AZ mit der Sicherheit des Herstellers. Service Brochure published by Mori Seiki

7) Murakami, T., Fujinuma, A. (2000).Ubiquitous networking: Towards a new paradigm. Nomura Research Institute Papers, No. 2

8) Putnik G. et al. (2004) Cells for Ubiquitous Production Systems, Proposal for R\&D Project, Project reference: POSC/EIA/60210/2004, submitted to Fundaçãopara a Ciência e a Tecnologia (FCT), Lisbon, Portugal

9) Putnik G. et al. (2006) Ubiquitous Production Systems and Enterprises - advanced enterprise networks for competitive global manufacturing, Proposal for R\&D Project, Project reference: PTDC/EME-GIN/72035/2006, submitted to Fundaçãopara a Ciência e a Tecnologia (FCT), Lisbon, Portugal

10) Putnik G.D., Cardeira C., Leitão P., Restivo F., Santos J., Sluga A., Butala P. (2007) Towards Ubiquitous Production Systems and Enterprises, in Proceedings of IEEE Int. Symp. on Ind. Electronics - ISIE 2007, Vigo, Spain
11) Putnik, G. D. (2010). Ubiquitous Manufacturing Systems vs. Ubiquitous Manufacturing Systems: Two Paradigms. In Proceedings of Proceedings of the CIRP ICME '10 - 7th CIRP International Conference on Intelligent Computation in Manufacturing Engineering - Innovative and Cognitive Production Technology and Systems

12) Putnik, G. D., \& Putnik, Z. (2010). A semiotic framework for manufacturing systems integration -Part I: Generative integration model. International Journal of Computer Integrated Manufacturing, 23: 8, 691 - 709

13) Schubert L. (2010) The future of cloud computing opportunities for European cloud computing beyond 2010, European Commission - Information Society and Media

14) Serrano V., Fischer T. (2007) Collaborative innovation in ubiquitous systems, J IntellManuf (2007) 18:599-615

15) Usmani, S., Azeem, N., \&Samreen, A. (2011). Dynamic Service Composition in SOA and QoS Related Issues International Journal of Computer Technology and Applications, 2, 1315-1321

16) Weber A. (1928), Theory of the Location of Industries, translated by C. J. Friedrich (Chicago: University of Chicago Press, 1928), p. 51 (emphases by Foust, Brady J. (1975))

17) Weiser,http://www.ubiq.com/hypertext/weiser/ UbiHome.html, Xerox PARC Sandbox Server.

18) Xu, X. (2012). From cloud computing to cloud manufacturing. Robotics and Computer-Integrated Manufacturing(28), 75-86

Paper sent to revision: 28.08.2012.

Paper ready for publication: 27.09.2012. 